\title{
Cytotoxicity and Pharmacokinetic Studies of PLGA Based Capecitabine Loaded Nanoparticles
}

\author{
Goutam Kumar Jena ${ }^{1, *}$, Chinam Niranjan Patra ${ }^{1}$, Prasanna Kumar Dixit ${ }^{2}$ \\ ${ }^{1}$ Department of Pharmaceutics, Roland Institute of Pharmaceutical Sciences, Berhampur, BPUT, Rourkela, Odisha, INDIA. \\ ${ }^{2}$ Department of Zoology, Berhampur University, Berhampur, Ganjam, Odisha, INDIA.
}

\begin{abstract}
Background: Colorectal cancer ranked fourth as devastating cancer globally based on statistical death analysis. The major challenge for treating colorectal cancer is to target the drug to the specific site of the colon. Purpose: The main objective of the present research was to develop PLGA based nanoparticles to target and sustain the drug release at the colon for effective treatment of colorectal cancer. The significance of using Eudragit S100 was to prevent drug release in the stomach and small intestine whereas the significance of PLGA is to sustain drug release by its mucoadhesion property. Methods: Nanoparticles were prepared by modified nanoprecipitation method and the cytotoxicity study was performed by MTT assay. Results: From the cytotoxicity study it was found that Capecitabine loaded PLGA based nanoparticles had more capacity to inhibit HT 29 cell lines than that of the pure drug for all concentrations (10 to 0.0001 ). Pharmacokinetic (PK) study for the aqueous suspension of Capecitabine and optimized formulation ratified the results of in vitro study. The Area under the curve (AUC) for nanoparticles formulation was found to be twice more than the pure drug indicating better bioavailability. Conclusion: The PLGA based nanoparticles can be better targeted to colon for effective treatment of colorectal cancer.
\end{abstract}

Key words: Capecitabine, Colorectal, Cancer, Cytotoxicity, MTT, PLGA.

\section{INTRODUCTION}

Colorectal cancer (CRC) is a disease caused due to western life style and changing food habit. ${ }^{1}$ Statistically about seven lacs people die every year due to colorectal cancer hence it is regarded as the fourth most devastating cancer in the world. ${ }^{2}$ Capecitabine (Cap) is a prodrug of 5-Fluorouracil which is recommended mainly for the treatment of advanced stage of CRC. ${ }^{3}$

On the therapeutic front, Cap can extend the average survival time of patient but cannot cure the disease completely. Cap has a very short half-life i.e. 45 to $60 \mathrm{~min}^{4}$ Due to very short half-life it has to be administered frequently to exert required therapeutic effect which leads to severe side effect. In order to reduce recurrence of administration, minimize side effects and to enhance the curative efficacy of the Cap, PLGA based $\mathrm{pH}$ sensitive nanoparticles were developed by nanoprecipitation method. The $\mathrm{pH}$ sensitive polymer used in the present research was Eudragit S100. It can ward off drug release in the overhead of the GIT and can target the colon directly with improved therapeutic effectiveness of cap. Poly (I-lactic acid) (PLA) and its copolymers with glycolic acid (PLGA) are the most extensively used biodegradable polymers for achieving sustain release with different drug delivery systems. ${ }^{5}$ Based on the composition and molecular weight of PLGA, different degradation rates from months to years can be attained.

PLGA was used in the present research to sustain drug release. Owing to the Mucoadhesive nature of PLGA it can easily adhere to the mucous layer of colon and prolong the drug release. ${ }^{6}$ The Cap loaded PLGA based nano formulations were optimized
Submission Date: 04-10-2019; Revision Date: 26-12-2019; Accepted Date: 24-01-2020

DOI: 10.5530/ijper.54.2.40 Correspondence: Dr. Goutam Kumar Jena, Associate Professor, Roland Institute of Pharmaceutical Sciences, Berhampur-760010, BPUT, Odisha, INDIA. Phone: +91 8249097072 E-mail: goutam2902@gmail. com

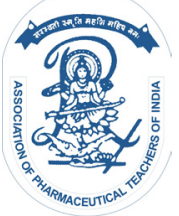

www.ijper.org 
considering mainly four factors i.e. particle size, zeta potential, polydispersity index and percentage entrapment efficiency. Thus, the goal of the present study was to design Eudragit S100 and PLGA based nanoparticles for site specific drug delivery of drug in colon followed by mucoadhesion and sustain release.

\section{MATERIALS AND METHODS}

\section{Materials}

Capecitabine was obtained as a gift sample from M/s RA CHEM, Hyderabad, India. PLGA (50:50) was purchased from Sigma Chemical CO, USA. Eudragit S100 was purchased from Sigma Chemical CO, USA. Poloxamer 188 and polyvinyl alcohol (PVA) were purchased from M/s Fine chemicals, Bengaluru, India.

\section{Methods}

\section{Preparative technique of designing PLGA based nanoparticles}

PLGA based nanoparticles were designed by nanoprecipitation method by slight modification. ${ }^{7-9}$ PLGA and Eudragit S100 (ES 100) polymers with an increasing ratio and a specified quantity of drug (Cap) as per formulation Table 1 were accurately weighed and dissolved in $10 \mathrm{ml}$ acetone which constituted the organic phase. Two different stabilizers Poloxamer 188 and polyvinyl alcohol (PVA) were used at $0.5 \%$ and $1 \% \mathrm{w} / \mathrm{v}$ aqueous solution respectively which constituted the aqueous phase. $19 \mathrm{ml}$ of the aqueous phase was taken in a beaker and $1 \mathrm{ml}$ of the organic phase was added to it. It was stirred magnetically with $1000 \mathrm{rpm}$ for $2 \mathrm{hr}$. The nanosuspension was subjected to centrifugation at 10,000 $\mathrm{rpm}$ for $25 \mathrm{~min}$. The sediment was collected and dispersed in distilled water and again subjected to lyophillization at $-45^{\circ} \mathrm{C}$ under a vacuume pressure of 0.05 torr using $5 \%$ mannitol as cryoprotectant. $^{10,11}$

\section{Analytical Techniques}

\section{Fourier Transform Infrared (FT-IR) Spectroscopy}

Potassium bromide pellets were prepared with Capecitabine, PLGA, Eudragit S100 alone and for dried nanoparticles and subjected to FT-IR study using IR affinity (Shimadzu, Japan).

\section{Differential Scanning Calorimetry (DSC)}

DSC studies were performed for Capecitabine, Eudragit S100, physical mixture and nanoparticles formulation using DSC-60 (Shimadzu, Japan). Samples were placed in aluminum pan and exposed to a heating rate of $10^{\circ} \mathrm{C} /$ min in the range of $25^{\circ} \mathrm{C}$ to $300^{\circ} \mathrm{C}$. The thermograms were observed for fusion and crystallization.

\section{Thermo Gravimetric Analysis (TGA)}

In this experiment TGA was carried out in a Perkin-Elmer (SINGAPORE), Model NO Pyris Diamond TG/DTA. Approximately $3 \mathrm{mg}$ of samples were placed in platinum crucibles. Each sample was heated from 60 to $500^{\circ} \mathrm{C}$ at a constant heating rate of $10^{\circ} \mathrm{C} / \mathrm{min}$ during the measurement process under a dynamic $\mathrm{N}_{2}$ atmosphere of $50 \mathrm{~mL} \mathrm{~min}{ }^{-1}$. TG analysis of CAP and PLGA were performed on this research.

\section{XRD analysis}

X-ray diffraction (XRD) patterns of Cap, PLGA and Cap loaded nanoparticles were observed using a ULTIMA-III RIGAKU MAKE (JAPAN) $\mathrm{Cu}$ target slit $10 \mathrm{~mm}$ at $40 \mathrm{kV}$ and $40 \mathrm{~mA}$ with $\mathrm{Cu} \mathrm{k} \alpha$ radiation $(\lambda=1.5406 \AA)$. The scanning range was $5-60^{\circ}(2 \theta)$ and the scanning rate was $4^{\circ} / \mathrm{min}$.

\section{Measurement of particle size and Zeta potential}

Nanoparticles formulations were evaluated for particle size, zeta potential and polydispersity index after 10 times dilution with distilled water using Malvern zeta sizer. Disposable zeta cells were used for the above tests.

\section{Evaluation of entrapment efficiency}

Nanoparticles were ultracentrifuged at 10,000 rpm for $30 \mathrm{~min}$ and the free drug content was determined from supernatant by UV spectroscopy at $239 \mathrm{~nm}$.

The drug entrapment efficiency (\% EE) of the nanoparticles were determined and calculated as per the following formula.

$$
\% \text { Entrapment efficiency }=\frac{\begin{array}{l}
\text { Total amount of drug }- \\
\text { free drug }
\end{array}}{\text { Total amount of drug }} \times 100
$$

\section{Transmission electron microscopy (TEM)}

Transmission electron microscopy (H 7500, M/s Hitachi, Tokyo, Japan, $120 \mathrm{kv}$ ) of optimized nanoparticles was performed by placing one drop of diluted nanosuspension on copper grid with subsequent staining with $0.1 \%$ phosphotungetic acid. Magnified image was taken in a photographic film.

\section{Ex vivo drug release study}

Ex vivo release study of Cap from PLGA based nanoparticles was investigated by using the dialysis bag. ${ }^{12}$ The dialysis membrane was flooded in $0.1 \mathrm{~N} \mathrm{HCl}$ one night before the experiment. The PLGA based nanosuspension 


\begin{tabular}{|c|c|c|c|c|c|c|}
\hline \multicolumn{7}{|c|}{ Table 1: Composition of PLGA based different nano formulations. } \\
\hline \multirow{2}{*}{ Code } & Drug $(\mathbf{m g})$ & \multicolumn{2}{c|}{ Polymer $(\mathbf{m g})$} & \multicolumn{2}{c|}{ Drug: polymer } & \multicolumn{2}{c|}{ Stabilizer (\%) } \\
\cline { 3 - 7 } & & PLGA & ES100 & Cap:PLGA:ES100 & Poloxamer 188 & PVA \\
\hline F1 & 10 & 20 & 20 & $1: 2: 2$ & 0.5 & - \\
\hline F2 & 10 & 30 & 30 & $1: 3: 3$ & 0.5 & - \\
\hline F3 & 10 & 40 & 40 & $1: 4: 4$ & 0.5 & - \\
\hline F4 & 10 & 50 & 50 & $1: 5: 5$ & 0.5 & - \\
\hline F5 & 10 & 20 & 20 & $1: 2: 2$ & - & 1 \\
\hline F6 & 10 & 30 & 30 & $1: 3: 3$ & - & 1 \\
\hline F7 & 10 & 40 & 40 & $1: 4: 4$ & - & 1 \\
\hline F8 & 10 & 50 & 50 & $1: 5: 5$ & - & 1 \\
\hline
\end{tabular}

equivalent to $10 \mathrm{mg}$ of Cap was placed in the dialysis bag and both ends were sealed. Three drug diffusion environments, $0.1 \mathrm{~N} \mathrm{HCl}$, phosphate buffer $\mathrm{pH} 6.8$ and 7.4 were selected to imitate the actual GIT environment. During the diffusion study the dialysis bag containing PLGA based nanosuspension equivalent to $10 \mathrm{mg}$ of Cap was held on first two solutions for a fixed period of time $2 \mathrm{hr}$ and $4 \mathrm{hr}$ to substitute different transit times in different parts of GIT before the carrier reached the colon area. The dialysis bag was then placed in the phosphate buffer $\mathrm{pH}$ 7.4. The dialysis bag was immersed in $100 \mathrm{ml}$ of diffusion media of the receptor phase, which was stirred at $100 \mathrm{rpm}$ and maintained at $37 \pm 0.5^{\circ} \mathrm{C}$. The receptor compartment was covered with aluminum foil to prevent the evaporation of the release media. $5 \mathrm{ml}$ of Sample was withdrawn at regular time intervals $(0,1,2,4,6,8,10,12$ and $24 \mathrm{hr}$ ) and the same volume was replaced by fresh release media. The samples were analyzed by UV spectroscopy at $239 \mathrm{~nm}$.

\section{In vivo Pharmacokinetic study}

Animals (White albino rabbits) were acclimatized for a period of 7 days. This experiment was performed with approval number 81 by institutional animal ethical committee having registration number 926/po/ Re/5106/CPCSEA of RIPS, Berhampur, India. Ryle's tube was used for the administration of pure drug and optimized formulation.

A reported method of UFLC was adopted for the quantitative estimation of Cap. ${ }^{13,14}$ Solvent extraction method was used for the construction of calibration curve of Cap in rabbit serum. Blood sample of $1 \mathrm{ml}$ were collected from marginal ear vein and allowed to coagulate for $30 \mathrm{~min}$. The blood sample was subjected to centrifugation for $10 \mathrm{~min}$ at 5000 revolutions per minute at $4^{\circ} \mathrm{C}$. Supernatant (serum) was transferred to six no of micro centrifuge tubes each having $100 \mu$ l.
The dilution of drug was carried out with phosphate buffer $\mathrm{PH} 3$ and acetonitrile to make different concentrations $(5,10,20,30,40$ and $50 \mathrm{ng} / \mathrm{ml}) .50 \mu \mathrm{L}$ of drug solution from each concentration was added and vortexed for $1 \mathrm{~min}$. Then $150 \mu \mathrm{L}$ of ethyl acetate as extracting solvent was mixed to each sample followed by centrifugation for $5 \mathrm{~min}$ at $2500 \mathrm{rpm}$. Subsequently $75 \mu \mathrm{L}$ of supernatant was collected. It was subjected to drying at $70^{\circ} \mathrm{C}$ and the dehydrated sampling was added to $1 \mathrm{ml}$ of mobile phase.

Serum concentration time curve of Cap was constructed and the following parameters like $\mathrm{C}_{\max }, \mathrm{T}_{\max }, \mathrm{AUC}$, elimination rate constant, elimination half-life and clearance were determined.

\section{Cytotoxicity study by using HT 29 cell lines by MTT assay}

MTT is a chemical substrate having pale yellow color. It is split by living cells only to produce formazon product with dark blue color. Living mitochondria is required for this process of splitting. The quantity of mitochondria split is directly proportional to the number of active cells which is determined colorimetrically. The test was undertaken at Deshpande laboratories Bhopal. In short MTT reagent was dissolved in dimethyl sulfoxide (DMSO) and diluted suitably to obtain desired concentrations range. The concentration of DMSO was limited to less than $0.1 \mathrm{ml}$ or all test samples. HT 29 cell lines were maintained at required conditions and were seeded in 96 well plates and subjected to various concentrations of test samples and incubated at $37^{\circ} \mathrm{C}, 5 \% \mathrm{CO}_{2}$ for $96 \mathrm{hr}$. The MTT reagent was added to the wells and incubated for $4 \mathrm{hr}$; product of formazon produced by living cells was dissolved in DMSO under a safety cabinet and measured at $550 \mathrm{~nm}$. The $\%$ inhibition and $\mathrm{IC}_{50}$ values were calculated. 


\section{RESULTS AND DISCUSSION}

\section{FT-IR investigation}

The chemical congeniality between Cap, PLGA and Eudragit S100 was evaluated by performing FT-IR study as given in Figure 1. The sharp peaks observed for cap at $1757 \mathrm{~cm}^{-1}$ indicates $\mathrm{C}=\mathrm{O}$ stretching vibrations, at $1333 \mathrm{~cm}^{-1}$ indicates $\mathrm{C}-\mathrm{N}$ bending vibrations, at $1242 \mathrm{~cm}^{-1}$ indicates $\mathrm{N}-\mathrm{H}$ bending vibrations and at $1117 \mathrm{~cm}^{-1}$ indicates $\mathrm{C}-\mathrm{F}$ stretching vibrations respectively almost same as previously reported. ${ }^{15}$ The nanoparticles loaded with cap also exhibits same peaks as that of the pure cap. The matching of peaks between nanoparticles and the pure cap revealed cap, PLGA and Eudragit S100 were quite compatible with each other. ${ }^{16,17}$ The FT-IR Spectra of Cap, PLGA, Eudragit S100 and Capecitabine loaded nanoparticles were presented in Figure 1.

\section{DSC study}

DSC study for Cap exhibited a sharp endothermic peak at $128.08^{\circ} \mathrm{C}$. It had on-set temperature of $122.71^{\circ} \mathrm{C}$ but end set temperature of $134.04^{\circ} \mathrm{C}$ as represented Figure 2. A sharp endothermic peak was observed for Cap and its physical mixture with PLGA and Eudragit $\mathrm{S} 100$ at $127.95^{\circ} \mathrm{C}$ but onset and end set temperatures of $123.25^{\circ} \mathrm{C}$ and $133.35^{\circ} \mathrm{C}$ as given in Figure 2. Nearly similar endothermic peaks were observed for Cap and its physical mixture with PLGA and Eudragit S100.

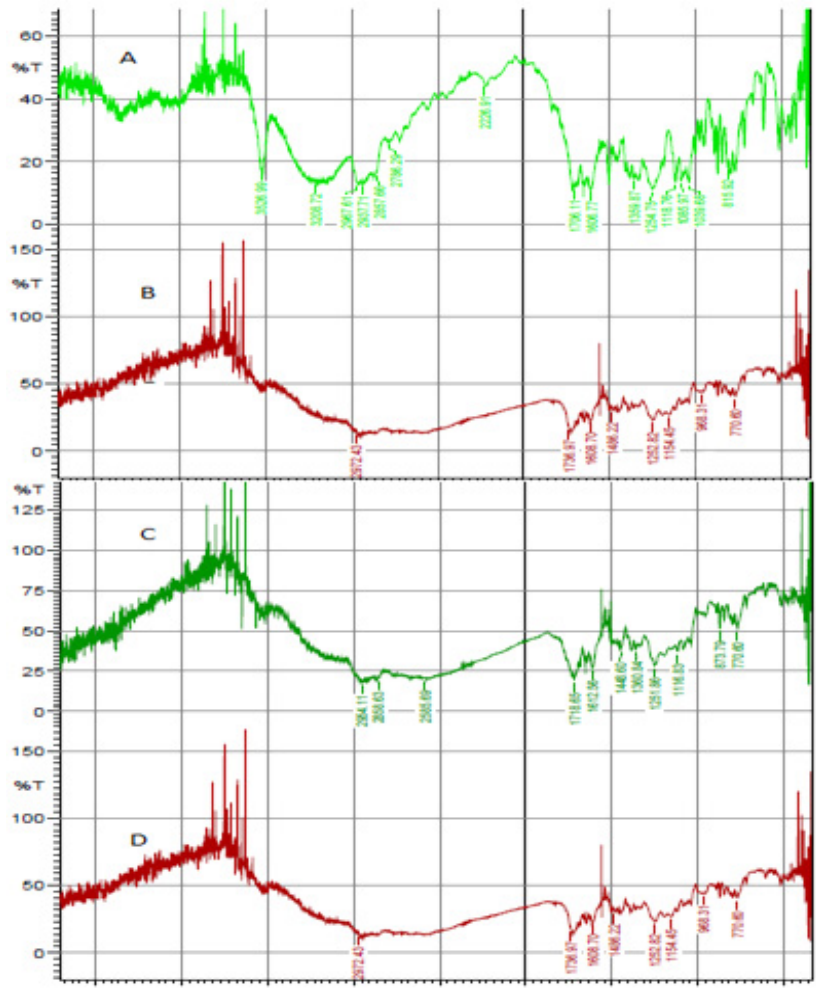

Figure 1: FT-IR Spectra of (A) Capecitabine (B) PLGA (C) Eudragit S100 and (D) Capecitabine loaded nanoparticles

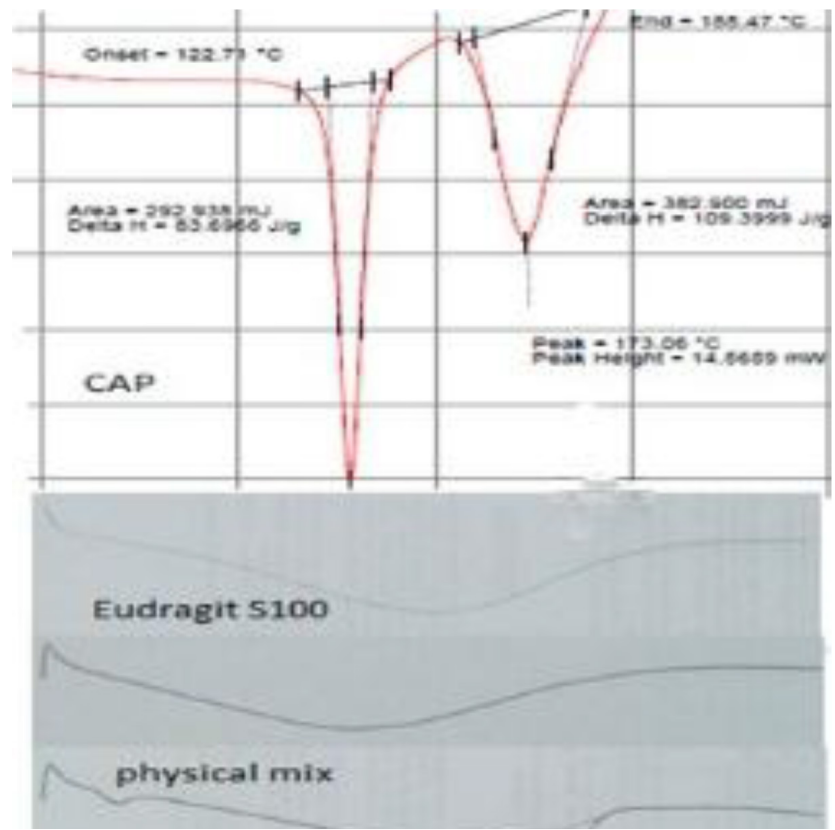

Figure 2: DSC thermograms of Cap (A), Eudragit S100 (B), physical mixture (C) and Capecitabine loaded PLGA NPs (D).
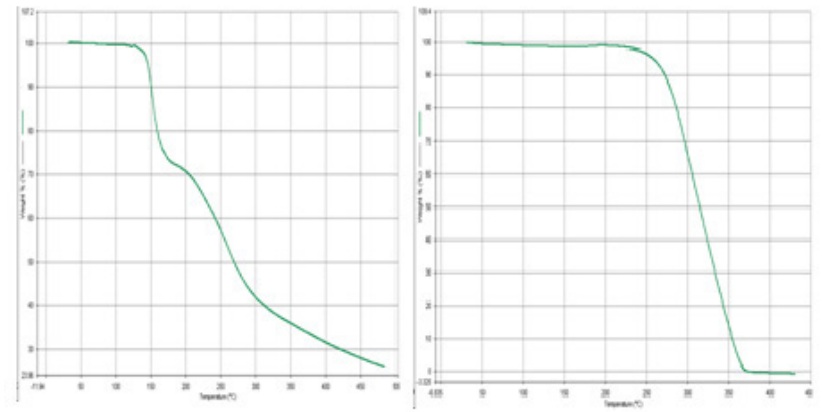

Figure 3: TGA thermograms of PLGA and Capecitabine.

Hence Cap was found to be compatible with both PLGA and Eudragit S100. DSC study for PLGA based Capecitabine loaded nanoparticles did not exhibit any peak. The absence of endothermic peaks can be attributed to complete entrapment of drug in PLGA based nanoparticles. ${ }^{18,19}$

\section{TGA study}

Thermo Gravimetric analysis (TGA) analyzes substances which show loss of mass or gain of mass as a result of decomposition, oxidation, loss of moisture as volatiles. In the present study, TGA analysis of Cap and PLGA showed constant weight over a wide range of temperature indicating thermal stability of the product as portrayed in Figure 3.

\section{X-RD Diffraction}

X-RD study of Cap with different polymers and nanoparticles revealed no crystallinity on nanoparticles. 


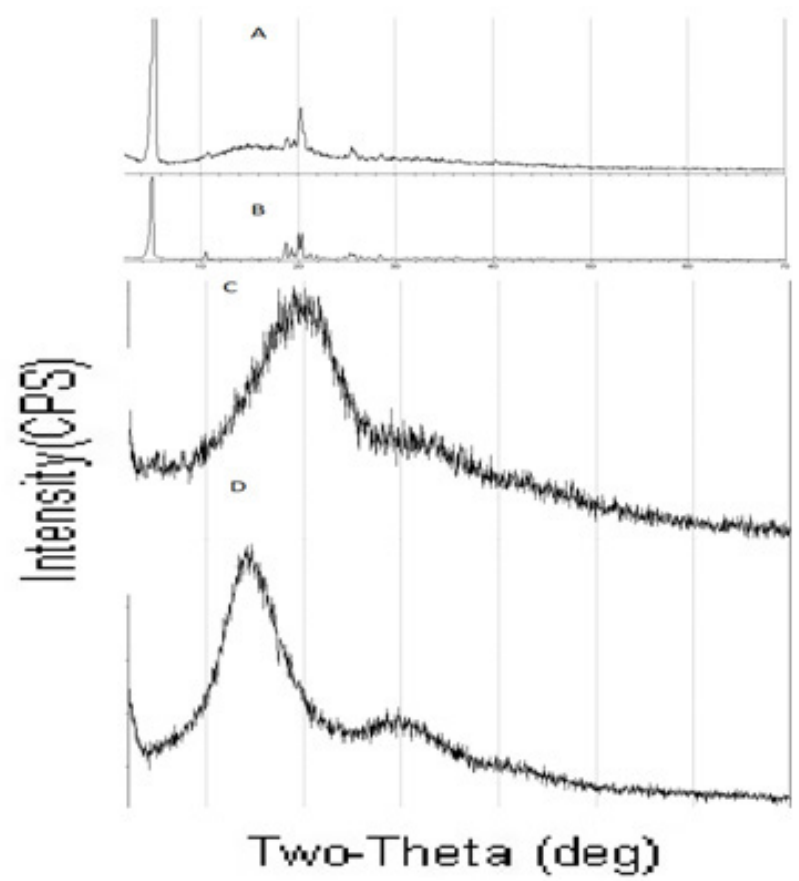

Figure 4: XRD spectra of A. Cap, B. Nanoparticles C. PLGA and D. Eudragit S100.

The patterns of X-RD diffraction of Cap revealed that intensity (counts) at different $2 \theta$ angles of $8.15,9.53$, $20.06,30.05,31.06$ and 33.29 which indicate that the drug is crystalline in nature. The X-RD diffraction pattern of optimized formulation also showed similar counts i.e. $2 \theta$ values as that of pure drug indicating that drug loaded nanoparticles are also crystalline in nature and showing same lattice arrangement as represented in Figure 4. However, the difference in crystal sizes and their outer appearances may lead to slight variations in the relative intensities of their peaks.

\section{Percentage Entrapment Efficiency (\%EE)}

The drug entrapment efficiency of the formulations (F1-F4) was found to be $45.4 \pm 1.11,64.6 \pm 1.12,66.5$ \pm 1.13 and $67.5 \pm 1.45 \%$ and formulations (F5-F8) was found to be $45.8 \pm 1.11,52.3 \pm 1.33,54.6 \pm 1.21$ and $55.8 \pm 1.56 \%$ as portrayed in Table 2 . Thus, there was a steady increase in the entrapment efficiency on increasing PLGA concentration in the formulation. The formulations F3 and F8 registered highest entrapment of $67.5 \pm 1.45 \%$ and $55.8 \pm 1.56 \%$ respectively.

\section{Zeta potential}

Zeta potential, particle size and polydispersity index (PDI) were determined by photon correlation spectroscopy (PCS) using zeta sizer 5000 (Malvern Instrument Ltd, U.K.). Averge particle size and polydispersity index were measured three times for each formulation by adopting suitable dilution. The zeta potential

\begin{tabular}{|c|c|c|c|c|}
\hline \multicolumn{5}{|c|}{ Table 2: Characterization of PLGA based } \\
nanoparticles. \\
\hline Formulations & $\begin{array}{c}\text { Particle } \\
\text { size }\end{array}$ & PDI & $\begin{array}{c}\text { Zeta } \\
\text { potential }\end{array}$ & $\%$ EE \\
\hline F1 & 195.1 & 0.398 & $-6.90 \pm 3.04$ & $45.4 \pm 1.11$ \\
\hline F2 & 219.9 & 0.368 & $-10.5 \pm 3.55$ & $64.6 \pm 1.12$ \\
\hline F3 & 215.7 & 0.138 & $-15 \pm 5.07$ & $66.5 \pm 1.13$ \\
\hline F4 & 263.9 & 0.293 & $-11.2 \pm 4.88$ & $67.5 \pm 1.45$ \\
\hline F5 & 345.1 & 1.000 & $-8.65 \pm 2.99$ & $45.8 \pm 1.11$ \\
\hline F6 & 363.4 & 0.891 & $-8.98 \pm 3.11$ & $52.3 \pm 1.33$ \\
\hline F7 & 379.8 & 1.000 & $-9.09 \pm 4.07$ & $54.6 \pm 1.21$ \\
\hline F8 & 315 & 0.480 & $-7.42 \pm 4.22$ & $55.8 \pm 1.56$ \\
\hline
\end{tabular}

Mean $\pm S D, n=3$

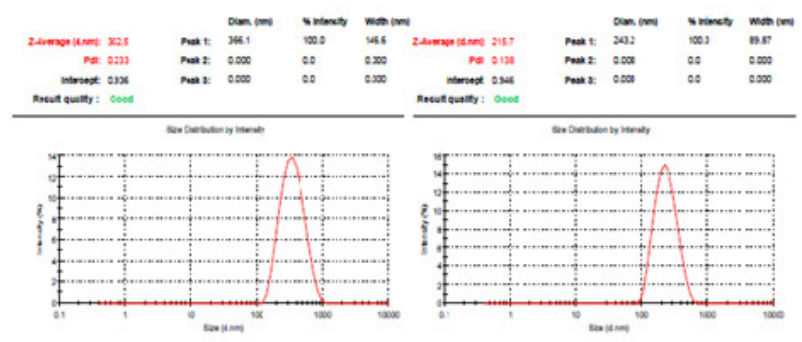

Figure 5: Average size of nanoparticles of formulation F4 and F5.

and the standard deviations were obtained directly from the instrument.

The average particle size of all formulations using poloxamer 188 as stabilizer were in the range of 195.1 $\mathrm{nm}$ to $263.9 \mathrm{~nm}$ whereas formulations with PVA as stabilizer were in the range of $315 \mathrm{~nm}$ to $379.8 \mathrm{~nm}$ as portrayed in Figure 5.

The zeta potential of all formulations using poloxamer 188 as stabilizer were in the range of $-6.90 \pm 3.04$ to $-15 \pm 5.07$ as presented in Figure 6. The PDI values of all formulations using poloxamer 188 as stabilizer were in the range of 0.138 to 0.398 and whereas PVA as stabilizer were in the range of 0.480 to 1.00 . Considering particle size, zeta potential, polydispersity index (PDI) values and percentage entrapment efficiency F3 and F8 were selected as optimized formulations.

\section{In-vitro drug diffusion study}

In-vitro drug diffusion study was performed for all nanoparticulate formulations. The drug diffusion study was performed using gradient $\mathrm{pH}$ simulating GI tract. The drug diffusion was studied initially in 0.1 $\mathrm{N} \mathrm{HCl}$ for $2 \mathrm{hr}$ followed by a change of medium to phosphate buffer $\mathrm{pH} 6.8$ for $4 \mathrm{hr}$ and subsequently for $24 \mathrm{hr}$ in phosphate buffer $\mathrm{pH}$ 7.4. All formulations (F1-F8) showed negligible drug release in both in $0.1 \mathrm{~N}$ $\mathrm{HCl}$ and phosphate buffer $\mathrm{pH}$ 6.8. ${ }^{20}$ This can be 


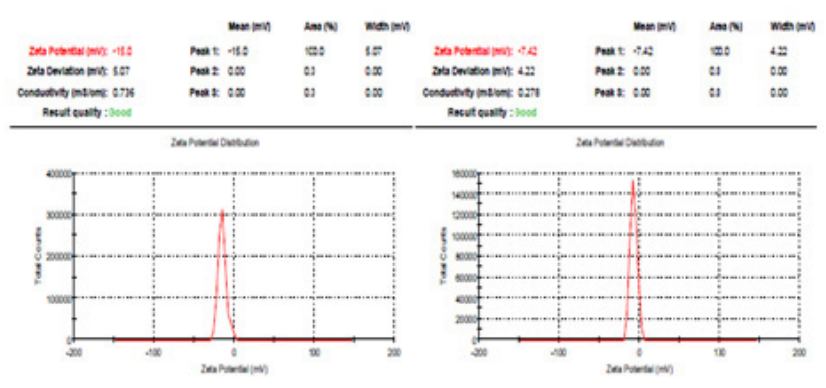

Figure 6: Zeta potential of nanoparticles of formulation F4 and F5.

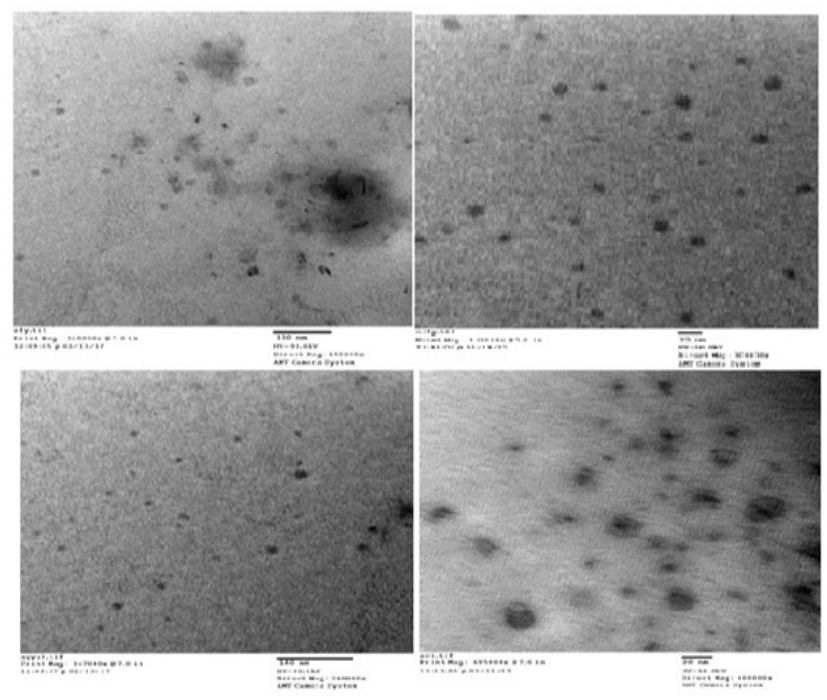

Figure 7: TEM images of nanoparticles.

attributed to the $\mathrm{pH}$ dependent solubility of Eudragit S100 (Soluble at $\mathrm{pH}>7$ ). It was observed that as the proportion of PLGA increased (F1-F4), the drug release rate decreased.

Diffusion of drug, erosion of polymers and swelling of polymers were considered to be the main mechanisms for drug release. This sustained release behavior can be attributed to slow degradation rate of PLGA.

\section{TEM analysis}

The TEM analysis performed for nanoparticles of optimized formulation (F3) were found to be discrete with mean particle size of about $100 \mathrm{~nm}$ (Figure 7).

\section{Cytotoxicity study}

Cytotoxicity study using HT 29 cell lines by MT'T assay indicated that Cap loaded nanoparticles were more cytotoxic than the pure drug solution as compared to previously reported ${ }^{21}$ and $\mathrm{IC}_{50}$ value of all formulations were found to be reduced to half than the pure drug solutions indicating more effective than pure drug (Figure 8)

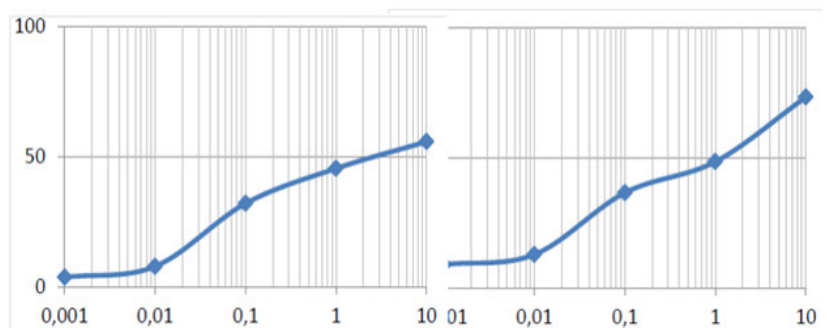

Figure 8: Percentage inhibition of pure drug of Cap and Cap loaded PLGA based Nanoparticles.

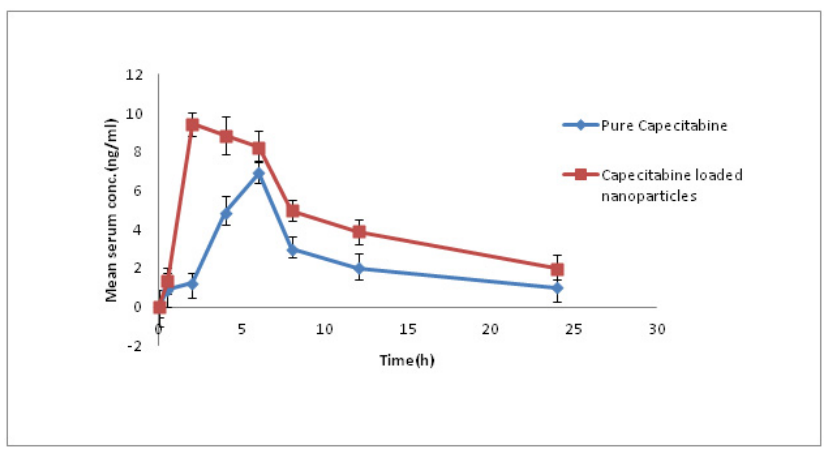

Figure 9: Comparative plots of cap and cap loaded PLGA based nanoparticles.

\section{Pharmacokinetic study}

UFLC (ultrafast liquid chromatographic) technique was adopted for analysis of Cap. This technique was very simple and rapid and here reverse phase method was followed. Chromatography was performed on a $25 \mathrm{~cm} \times 4.6 \mathrm{~mm}$ i.e. $5 \mu \mathrm{m}$ particle, $\mathrm{C}_{18}$ column with 55: $45(\% \mathrm{v} / \mathrm{v})$ acetonitrile: phosphate buffer $\mathrm{pH} 3$ as a mobile phase at a flow rate of $10 \mathrm{ml} / \mathrm{min}$, PDA detection at $239 \mathrm{~nm}$. Cap was eluted with a retention time of $4.292 \mathrm{~min}$. The method was found to be linear in the concentration range of $5-50 \mathrm{ng} / \mathrm{ml}$ of Cap with coefficient of correlation 0.999 .

The serum sample of rabbit were analyzed by HPLC method with acetonitrile and phosphate buffer $\mathrm{pH} 3$ in the ratio of $55: 45$, retention time of $4.292 \mathrm{~min}$, column $\mathrm{C}_{-18}$. The standard curve of pure drug in serum was prepared in the concentration range of 5 to $50 \mathrm{ng} / \mathrm{ml}$. Ethyl acetate was used as extracting solvent.

Pharmacokinetic study for the aqueous suspension of pure drug Capecitabine and optimized formulation (F3) ratified the results of in vitro study. $\mathrm{C}_{\max }$ of optimized formulation F3 was found to be higher as compared to pure drug indicating better absorption of drug from nanoparticles and the $\mathrm{T}_{\max }$ for pure drug was found to be of less $(2 \mathrm{hr})$ as compared to formulation $(2.5 \mathrm{~h})$ as given in Figure 9. The AUC for nanoparticles formulation was found to be approximately two times 
Table 3: Pharmacokinetic parameters utilizing Microsoft Excel 2007.

\begin{tabular}{|c|c|c|}
\hline parameters & (Cap) $(\boldsymbol{n}=\mathbf{6})$ & $\begin{array}{c}\text { Cap loaded PLGA } \\
\text { based nanoparticles } \\
(\boldsymbol{n}=\mathbf{6})\end{array}$ \\
\hline $\mathrm{C}_{\max }\left(\mathrm{ngmL}^{-1}\right)$ & 6.9345 & 9.4569 \\
\hline $\mathrm{T}_{\max }(\mathrm{h})$ & 6 & 2.5 \\
\hline $\mathrm{AUC}_{0-\mathrm{t}}(\mathrm{ng}-\mathrm{h} / \mathrm{mL})$ & 95.6489 & 185.6783 \\
\hline $\mathrm{AUC}_{0-\infty}(\mathrm{ng}-\mathrm{h} / \mathrm{mL})$ & 96.8556 & 200.7855 \\
\hline $\mathrm{t}_{1 / 2}(\mathrm{~h})$ & 8.599 & 26.86 \\
\hline $\mathrm{CL}(\mathrm{L} / \mathrm{h})$ & 13.068 & 16.488 \\
\hline $\mathrm{VD}(\mathrm{L})$ & 3.413 & 6.835 \\
\hline
\end{tabular}

more than the pure drug indicating better bioavailability (Table 3).

\section{CONCLUSION}

Capecitabine loaded PLGA in combination with Eudragit S100 can be developed by nanoprecipitation method and can be selectively targeted to colon with sustained release for the effective treatment of colorectal cancer. The cytotoxic effect of Capecitabine loaded nanoparticles was found to be more cytotoxic to tumor cells than pure Cap. Hence our developed nano formulations would be highly toxic to tumor cells and less toxic to normal cells which indicated it would produce fewer side effects.

\section{ACKNOWLEDGEMENT}

The authors are very much thankful to M/S RA CHEM, Hyderabad, India for providing Capecitabine as well as PLGA as gift sample and to the Management and Principal of Roland Institute of Pharmaceutical Sciences, Berhampur for providing research facilities for carrying out this research and to Deshpande Laboratories Pvt. Ltd., MP for performing cytotoxicity studies using HT 29 cell lines by MTT assay.

\section{CONFLICT OF INTEREST}

The authors declare no conflict of interest

\section{ABBREVIATIONS}

CRC: Colorectal cancer; Cap: Capecitabine; PLGA: Poly (lactic-co-glycolic acid); FT-IR: Fourier Transform Infrared; DSC: Differential Scanning Calorimetry; TGA: Thermo Gravimetric Analysis; XRD: X-ray diffraction; TEM: Transmission electron microscopy; \%EE: Percentage entrapment efficiency; DMSO: Di Methyl Sulfoxide; PDI: Polydispersity index; PCS:
Photon Correlation Spectroscopy; PVA: Poly Vinyl Alcohol.

\section{REFERENCES}

1. Levine JS, Ahnen DJ. Clinical practice: Adenomatous polyps of the colon. NEJM. 2006;355(24):2551-7.

2. Jeffrey A, Meyerhardt MD, Edward L, Giovannucci MD, Shuji O, Gregory J, et al. Physical Activity and Male Colorectal Cancer Survival. Arch Intern Med. 2009;169(22):2102-8.

3. Meyerhardt JA, Heseltine D, Niedzwiecki D, Hollis D, Saltz LB, Mayer RJ, et al. The impact of physical activity on cancer recurrence and survival in patients with stage III colon cancer: Findings from CALGB 89803. J Clin Oncol. 2006;24(22):3535-41.

4. Kelly C, Bhuva N, Harrison M, Buckley A, Saunders M. Use of raltitrexed asan alternative to 5 fluorouracil and capecitabine in cancer patients with cardiachistory. Eur J Cancer. 2013;49(10):2303-10.

5. Mainardes RM, Evangelista RC. PLGA nanoparticles containing praziquantel: Effect of formulation variables on size distribution. Int $\mathrm{J}$ of Pharm. 2005;290(1-2):137-44.

6. Vega E, Gamisans F, Garc'ia ML, Chauvet A, Lacoulonche F, Egea MA. PLGA nanospheres for the ocular delivery of flurbiprofen: Drug release and interactions. J Pharm Sci. 2008;97(12):5306-17.

7. Lal PS, Jana U, Manna PK, Mohanta GP, Manavalan R. Nanoparticles: An overview of preparation and characterization. JAPS. 2011;1(6):228-34.

8. Prasad RJ, Geckeler KE. Polymer nanoparticles: Preparation techniques and size-control parameters. Progress in Polymer Science. 2011;36(7):887-913.

9. Farnaz E, Mohammad HG, Esmaeili B, Khoshayand MR, Atyabi F, Dinarvand R. PLGA nanoparticles of different surface properties: Preparation and evaluation of their body distribution. Int J Pharm. 2008;349(1-2):249-55.

10. Govender T, Snjezana S, Martin C, Garnett LI, Davis SS. PLGA nanoparticles prepared by nanoprecipitation: Drug loading and release studies of a water soluble drug. Journal of Controlled Release. 1999;57(2):171-85.

11. Yang L, Chu JS, Fix JA. Colon-specific drug delivery: New approaches and in vitrolin vivo evaluation. Int J Pharm. 2002;235(1-2):1-15.

12. Olukman M. Release of anticancer drug 5-fluorouracil from different ionically cross linked alginate beads. J Biomater Nanobiotechnol. 2012;3(04):469-79.

13. Sun Li, Chen Y, Zhou Y, Dongdong G, Fan Y, Fangyan G, et al. Preparation of 5-fluorouracil-loaded chitosan nanoparticles and study of the sustained release in vitro and in vivo. Asian Journal of Pharmaceutical Sciences. 2017;12(5):418-23.

14. Guterres SS, Fessi H, Barrat G, Devissaguet JP, Puisiex F. Poly (DL-Lactide) nanocapsules containing diclofenac: Formulation and stability study. Int J Pharm. 1995;113(1):57-63.

15. Sutar PS, Hardy JG, Fara JW. Formulation and evaluation of PLGA nanoparticles loaded capecitabine for prostate cancer. Int J Clin Exp Med. 2015;8(10):19670-81.

16. Garima J, Kumar A, Sawant KK. Bioavailability enhancement, Caco-2 cells uptake and intestinal transport of orally administered lopinavir loaded PLGA nanoparticles. Drug Delivery. 2016;23(9):1-31.

17. Zohreh $H G$, Fatemeh $A L$, Ahad $M$, Mohammad $R$, Maryam $H$. Evaluation of anticancer activity of PLGA nanoparticles containing crocetin. Artificial Cells, Nanomedicine and Biotechnology. 2016. DOI: 10.1080/21691401.2016.1198359

18. Shan-Shan Q, Jia-Hui S, Hao-Han Y, Shu-Qin Y. Co-delivery nanoparticles of anti-cancer drugs for improving chemotherapy efficacy. Drug Delivery. 2017;24(1):1909-26. DOI: 10.1080/10717544.2017.1410256

19. Tao D, Zhuobin X, Fumou S, Yang W, Juan Z, Chen L, et al. HPA aptamer functionalized paclitaxel-loaded PLGA nanoparticles for enhanced anticancer therapy through targeted effects and microenvironment modulation. Biomedicine and Pharmacotherapy. 2019;117:109-21.

20. Smita P, Arehalli SM, Mukesh U, Murthy SR. PLGA nanoparticles loaded with etoposide and quercetin dihydrate individually: In vitro cell line study to ensure advantage of combination therapy. Cancer Nano. 2012;3(1):25-36.

21. Long-Bin C, Sha Z, Wei Z. Highly Stable PEGylated Poly (lactic-coglycolic acid) (PLGA) Nanoparticles for the Effective Delivery of Docetaxel in Prostate Cancers. Nanoscale Research Letters. 2016;11(1):305. 


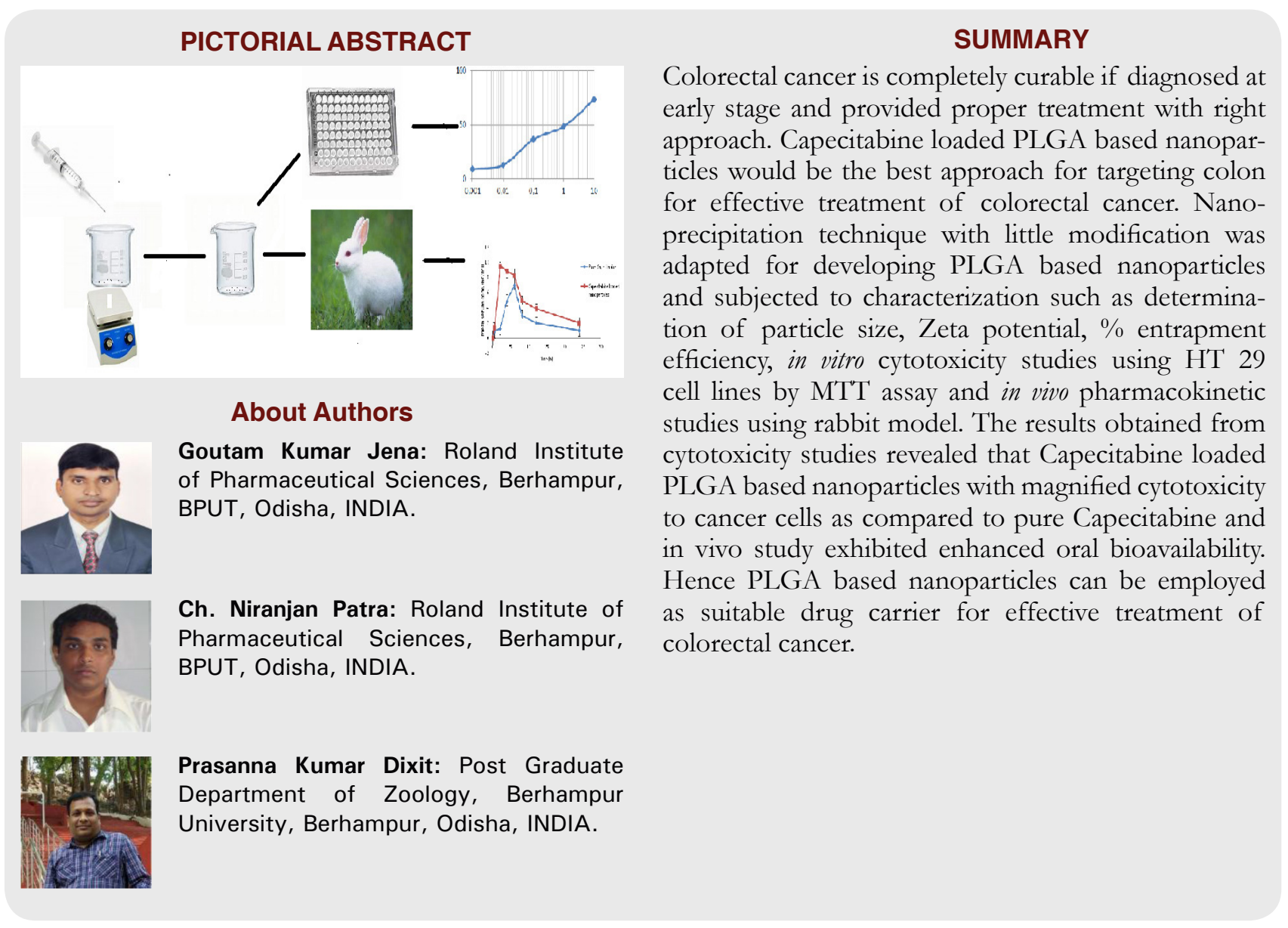

Cite this article: Jena GK, Patra CHN, Dixit PK. Cytotoxicity and Pharmacokinetic Studies of PLGA Based Capecitabine Loaded Nanoparticles. Indian J of Pharmaceutical Education and Research. 2020;54(2):349-56. 